\title{
Fe/Cu mesoporous carbon supported alumina hollow ceramic membrane for the degradation of ofloxacin
}

\author{
Chunming Zheng ${ }^{1, a}$, Shubin Chang ${ }^{1}$, Dongying $\operatorname{Lian}^{1}$, Chao $\mathrm{Ma}^{1}$, Jun $\mathrm{Xia}^{1}$ \& \\ Xiaohong Sun ${ }^{2, b}$
}

\begin{abstract}
${ }^{1}$ State Key Laboratory of Hollow-fiber Membrane Materials and Membrane Processes, School of Environmental and Chemical Engineering, Tianjin Polytechnic University, Tianjin 300387, China

${ }^{2}$ Key Laboratory of Advanced Ceramics and Machining Technology, Ministry of Education, School of Materials Science and Engineering, Tianjin University, Tianjin 300072, China
\end{abstract}

azhengchunming@tjpu.edu.cn,,sunxh@tju.edu.cn

Keywords: mesoporous carbon; spin-coating; ceramic membrane;ofloxacin.

Abstract. Nanoscale bimetallic $\mathrm{Fe} / \mathrm{Cu}$ mesoporous carbon supported alumina hollow ceramic membrane were successfully synthesized by spin-coating method. The morphology and physico-chemical properties of catalyst were characterized by XRD, SEM, TEM. The performance of the catalysts was evaluated by the adsorption degradation of ofloxacin. The results showed that the adsorption ability of supported membrane is stronger than that of pure alumina hollow ceramic membrane. Compared with single metal $\mathrm{Fe}$ mesoporous carbon membrane, the bimetallic $\mathrm{Fe} / \mathrm{Cu}$ mesoporous carbon membrane exhibited higher removal ratio (45\% versus $90 \%$ ). The possible adsorption and degradation mechanisms are also proposed.

\section{Introduction}

The wastewater discharged from factories has characteristics of high concentration, high toxicity and high organic content, such as printing and dyeing wastewater, pharmaceutical wastewater and leather wastewater. It is difficult to achieve the emission standards with the treatment of general municipal sewage treatment system if it is discharged directly into the environment, which seriously affects the ecological environment. Therefore, efforts to develop more efficient, economical and clean water treatment technologies have become an urgent demand for wastewater treatment. At present, the heterogeneous Fenton has attracted widespread attention due to its excellent properties. The choose of catalyst is vital for the heterogeneous Fenton reaction. Mesoporous materials with large specific surface area and uniform pores are widely used, which could provide more active sites and improve the pollutant removal efficiency. But the utilization rate of the catalyst is not high in traditional heterogeneous Fenton reaction. To solve these problems, bimetallic $\mathrm{Fe} / \mathrm{Cu}$ mesoporous carbon supported alumina hollow ceramic membrane were synthesized in this report. The combination of membrane filtration and mesoporous materials could not only retain the catalytic advantages of mesoporous materials, but also complete catalytic separation simultaneously, which improved utilization ratio of catalyst. The performance of the catalysts was evaluated by the adsorption degradation of ofloxacin, and the possible mechanisms are also proposed. 


\section{Experimental}

Chemicals. Alumina hollow ceramic tube (length $6 \mathrm{~cm}$, outside diameter $14 \mathrm{~mm}$, internal diameter $8 \mathrm{~mm}$, pore size $500 \mathrm{~nm}$ ) was purchased from Nanjing Jiuwugaoke Co. Ltd. Pluronics (F127) was purchased from Sigma Aldrich. Ethanol solution of phenolic resin (20 wt \%) was prepared in laboratory. Copper(II) nitrate hydrate $\left(\mathrm{Cu}\left(\mathrm{NO}_{3}\right)_{2} \cdot 3 \mathrm{H}_{2} \mathrm{O}\right)$, iron(III) nitrate nonahydrate $\left(\mathrm{Fe}\left(\mathrm{NO}_{3}\right)_{3} \cdot 9 \mathrm{H}_{2} \mathrm{O}\right)$ were analytical grade and purchased from Tianjin Guangfu Chemical Co. Ltd. Absolute ethyl alcohol $\left(\mathrm{CH}_{3} \mathrm{CH}_{2} \mathrm{OH}\right)$ was used as solvent.

Synthesis of catalysts. Bimetallic $\mathrm{Fe} / \mathrm{Cu}$ mesoporous carbon precursor were prepared according to the following procedure: Pluronics (F127, $1.0 \mathrm{~g}$ ) were dissolved in absolute ethyl alcohol (14.0 g), reflux $30 \mathrm{~min}$ at $50{ }^{\circ} \mathrm{C}$. Then $5.0 \mathrm{~g}$ ethanol solution of phenolic resin $(20 \mathrm{wt} \%)$ was added and stirring vigorously for $10 \mathrm{~min} . \mathrm{Fe}\left(\mathrm{NO}_{3}\right)_{3} \cdot 9 \mathrm{H}_{2} \mathrm{O}(0.23 \mathrm{~g})$ and $\mathrm{Cu}\left(\mathrm{NO}_{3}\right)_{2} \cdot 3 \mathrm{H}_{2} \mathrm{O}(0.07 \mathrm{~g})$ mixing ethanol solution was added dropwise. The resultant solution was stirred continuously for $30 \mathrm{~min}$. Then the solution was poured into a surface dish and evaporate at room temperature. A spin-coating method was used to coat layer in alumina hollow ceramic tube surface with obtained bimetallic $\mathrm{Fe} / \mathrm{Cu}$ mesoporous carbon precursor. In brief, the alumina ceramic tube was blocking at both ends. Then the $\mathrm{Fe} / \mathrm{Cu}$ mesoporous carbon precursor material was uniformly coated on the outer surface of the alumina ceramic tube. The obtained ceramic membrane was solidified at $100{ }^{\circ} \mathrm{C}$ in vacuum oven of $24 \mathrm{~h}$, then calcined at $600{ }^{\circ} \mathrm{C}$ for $5 \mathrm{~h}$ (heating rate of $1{ }^{\circ} \mathrm{C} / \mathrm{min}$ ) in $\operatorname{argon}$ gas and get the $\mathrm{Fe} / \mathrm{Cu}$ mesoporous carbon supported alumina hollow ceramic membrane.

Characterization. The bimetallic $\mathrm{Fe} / \mathrm{Cu}$ mesoporous carbon hybrid nanoparticles were characterized by X-ray diffraction with $\mathrm{Cu}$ Ka radiation $(=0.154 \mathrm{~nm})$ as the X-ray source. The transmission electron microscopy (TEM) was done on a Hitachi H-7650 operated at $100 \mathrm{kV}$.

Catalytic degradation of ofloxacin. The degradation of ofloxacin $(30 \mathrm{mg} / \mathrm{l})$ was conducted on the ceramic membrane surface. First, the ceramic membrane (seal up one end) was placed into the solution of ofloxacin, the other end of ceramic membrane was connected with the circulation pump to provide transmembrane pressure. Then, $\mathrm{pH}$ was adjusted to 5 and $\mathrm{H}_{2} \mathrm{O}_{2}$ (20:1) was added according to with molar ratio of loaded metal on ceramic membrane surface. Ofloxacin was degraded in the activity layer of bimetallic $\mathrm{Fe} / \mathrm{Cu}$ mesoporous carbon on ceramic membrane surface. Through the ceramic tube carrier, the purified water was separated into the internal hollow part of membrane. The samples of through ceramic membrane were collected for UV-Vis testing at $288 \mathrm{~nm}$. Finally, the ceramic tube carrier was recycled after washing with deionized water and alcohol and drying in vacuum oven.

\section{Results and discussion}

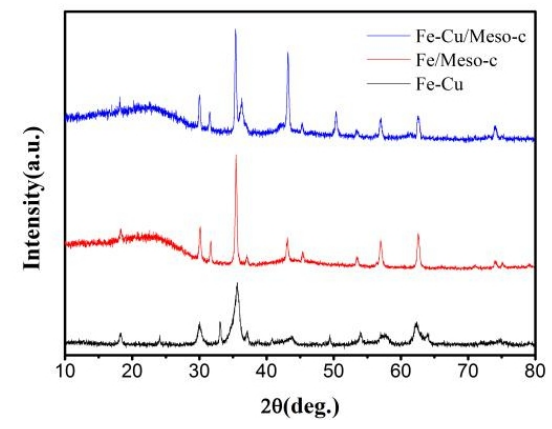

Fig.1. High-angle XRD patterns of pure $\mathrm{Fe}-\mathrm{Cu}, \mathrm{Fe} / \mathrm{Meso}-\mathrm{C}$ and $\mathrm{Fe}-\mathrm{Cu} / \mathrm{Meso}-\mathrm{C}$ catalysts 
Characterization of $\mathrm{Fe} / \mathrm{Cu}$ mesoporous carbon. Fig.1 A shows the high-angle XRD patterns of pure $\mathrm{Fe}-\mathrm{Cu}, \mathrm{Fe} / \mathrm{Meso}-\mathrm{C}$ and $\mathrm{Fe}-\mathrm{Cu} / \mathrm{Meso}-\mathrm{C}$ catalysts. The diffraction peak broadened at $25^{\circ}$ when metal oxides incorporated into mesoporous carbon, which is related to the metal nanoparticles occupied channels of mesoporous carbon. From Fig.1, the diffraction of $30^{\circ}, 35^{\circ}, 43^{\circ}, 57^{\circ}$ and $63^{\circ}$ were assigned to (220), (311), (400), (511) and (440) reflections of crystalline $\square-\mathrm{Fe}_{2} \mathrm{O}_{3}$ phases[1]. In addition, the diffraction of $32.5^{\circ}, 38.7^{\circ}, 46.3^{\circ}, 48.7^{\circ}$, correspond to crystalline $\mathrm{CuO}$ phases. These results were consistent with previous studies[2], indicating that the successful $\mathrm{Fe} / \mathrm{Cu}$ metal oxide crystallization and uniformly dispersion in the carbon matrix.

To further investigate the porous structure and distribution state of metal species, the Meso-C and $\mathrm{Fe} / \mathrm{Cu}$ Meso- $\mathrm{C}$ were investigated by transmission electron microscopy (TEM) and the obtained images are shown in Fig.2. As shown in Fig.2a, the mesoporous carbon exhibits well-arranged lattice stripe and regular hexagonal pore distribution. Although bimetallic metals of $\mathrm{Fe}$ and $\mathrm{Cu}$ incorporated in the carbon framework (Fig.2b), the ordered arrangement of the lattice fringes could be observed, which indicates that the incorporation of metal nanoparticles did not destroy the structure of mesoporous carbon. In addition, the graphs clearly demonstrate that the $\mathrm{Fe} / \mathrm{Cu}$ nanoparticle were well dispersed in the structure of mesoporous carbon. These characteristics ensured high catalytic activity for ofloxacin.

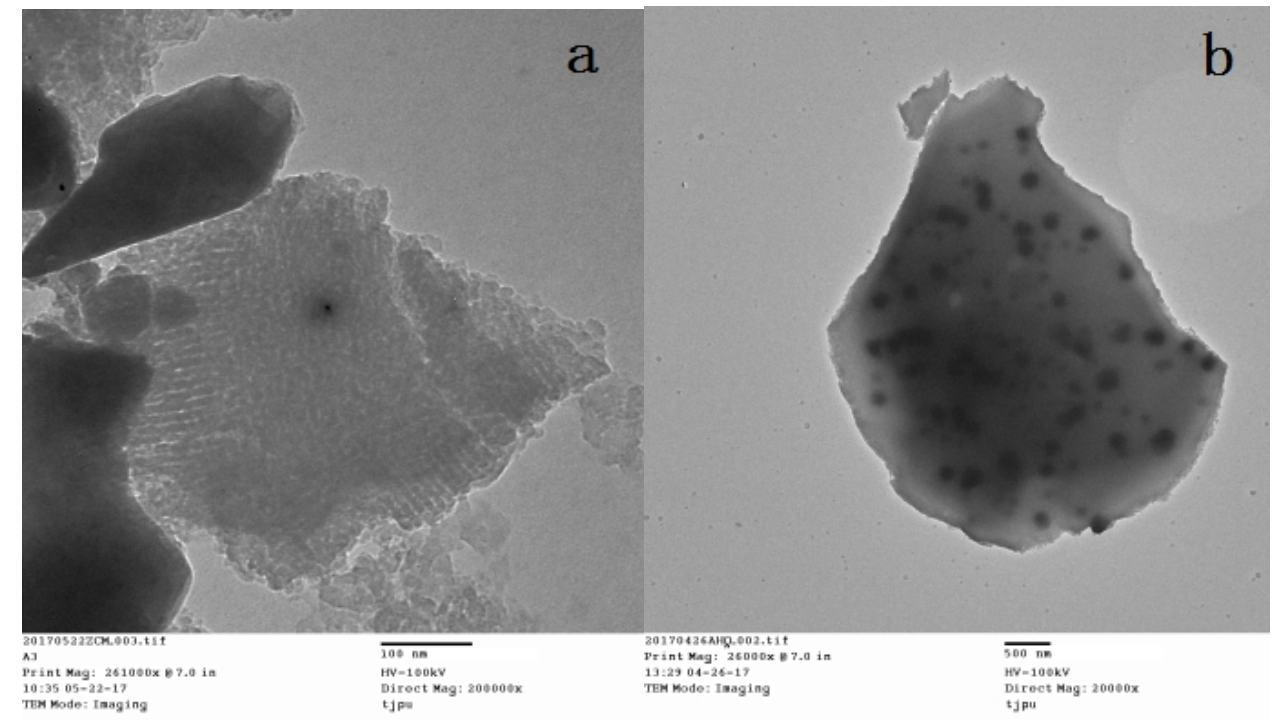

Fig.2. TEM images of Meso-C (a) and Fe/Cu Meso-C (b).

Comparison of adsorption and degradation. The adsorption degradation of ofloxacin were implemented by catalyst materials. As shown in Fig.3a, the adsorption of ofloxacin only showed slight effects by uncoated pure alumina hollow ceramic tube because of relatively larger pore size. However, the $\mathrm{Fe} / \mathrm{Cu}$ mesoporous carbon coated alumina hollow ceramic membrane continuous increased to $50 \%$ within $250 \mathrm{~min}$ for adsorption efficiency of ofloxacin compared with pure ceramic tube $(5 \%)$. The combination of coated ceramic membrane with $\mathrm{H}_{2} \mathrm{O}_{2}$ increased adsorption degradation efficiency of ofloxacin, reached $90 \%$ in $30 \mathrm{~min}$. These was mainly due to the large specific surface area of $\mathrm{Fe} / \mathrm{Cu}$ mesoporous carbon active layer on ceramic membrane surfaces, high utilization of active sites and the separation of ceramic tube supports. 
Metal contrast of active layer. The degradation of ofloxacin by different metal active layers was shown in Fig.4b. As illustrated in Fig.4b, compared with the bimetallic $\mathrm{Fe} / \mathrm{Cu}$ mesoporous carbon active layer, the degradation of ofloxacin by the single metal iron mesoporous carbon activated layer ceramic membrane was significantly decreased by $50 \%$. It is indicating that the $\mathrm{Fe}(\mathrm{III})$ and $\mathrm{Cu}(\mathrm{II})$ on the surface of the active layer could catalyze $\mathrm{H}_{2} \mathrm{O}_{2}$ decomposition to generate $\cdot \mathrm{OH}$ radicals[3] (Wang, Zhao et al. 2013), and the synergistic effect of $\mathrm{Fe}$ and $\mathrm{Cu}$ also could promote the decomposition of $\mathrm{H}_{2} \mathrm{O}_{2}$ and produce more $\cdot \mathrm{OH}$ radicals, which increased the degradation rate.
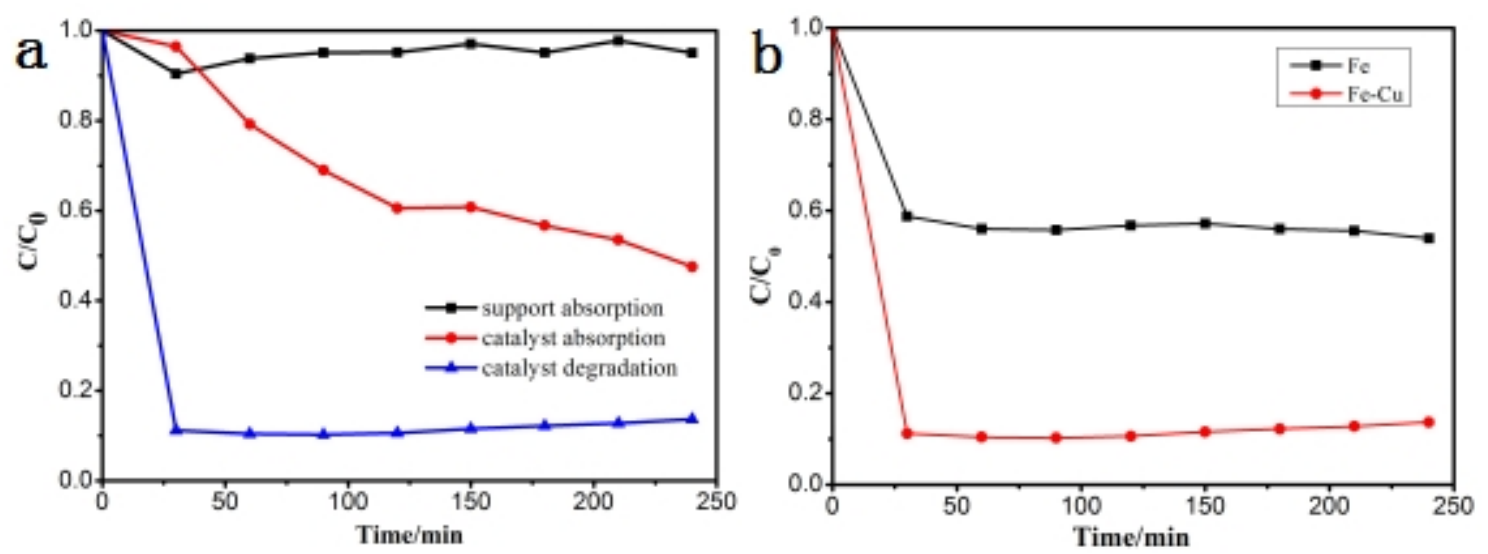

Fig.3. Comparison of adsorption and degradation of Fe-Cu/Meso-C catalysts(a);Degradation comparison of single iron and $\mathrm{Fe}-\mathrm{Cu}$ metal oxides of active layer for degradation of ofloxacin(b).

\section{Conclusions}

In summary, bimetallic $\mathrm{Fe} / \mathrm{Cu}$ mesoporous carbon supported alumina hollow ceramic membrane combined membrane filtration and degradation with mesoporous materials. It not only retains the characteristics of large pore size and uniform pore size of mesoporous materials, but also integrates membrane separation and further improves the material utilization and catalytic performance.

\section{Acknowledgements}

This work was supported by the National Natural Science Foundation of China (51472179, 51572192). General Program of Municipal Natural Science Foundation of Tianjin (17JCYBJC17000, 17JCYBJC22700).

\section{References}

[1] C.M. Zheng, X.Z. Cheng and C.W. Yang: Rsc. Adv. Vol. 5(2015)98842-98852, p. 120.

[2] E. A. A. Said, M. M. M. A. El-Wahab and M. N. Goda: App. Surf. Sci. 390(2016)649-665.

[3] Y.Wang, H. Zhao and M. Li: App. Catal. B-Environ.Vol. 147(2014)534-545, p. 8. 